Check for updates

Kent

Cite this as: $B M J 2022 ; 376: 029$ http://dx.doi.org/10.1136/bmj.o29 Published: 07 January 2022

\section{Covid-19: Babies born during the pandemic show slight development delays}

\author{
Jacqui Wise
}

Babies born during the pandemic's first year scored slightly lower on a developmental screening test at six months compared with babies born just before the pandemic, a small study has found.

The research, published in JAMA Paediatrics, found no signal to suggest that exposure to SARS-CoV-2 infection in the womb was linked to neurodevelopmental deficits. ${ }^{1}$ Instead the researchers suggest that covid-19 related maternal stress may have had a role.

The cohort study of 255 infants born between March and December 2020 at Columbia University Irving Medical Center in New York included 114 who were exposed in utero to SARS-CoV-2 and 141 who were not. Most of the mothers experienced asymptomatic or mild disease and were infected in the second or third trimester.

The researchers analysed data from the Ages and Stages Questionnaire given to parents to evaluate neurodevelopment at six months. Data were compared with a historical cohort of 62 infants born at the same institution before the pandemic.

In utero exposure to SARS-CoV-2 was not associated with significant differences in any subdomain on the questionnaire, regardless of infection severity or timing. But infants born during the pandemic had significantly lower gross motor, fine motor, and personal-social scores than the historical cohort. This applied whether mothers contracted the virus or not.

Dani Dumitriu, the lead investigator and an assistant professor of paediatrics and psychiatry, said, "We were surprised to find absolutely no signal suggesting that exposure to covid while in utero was linked to neurodevelopmental deficits. Rather, being in the womb of a mother experiencing the pandemic was associated with slightly lower scores in areas such as motor and social skills, though not in others, such as communication or problem solving skills." She added, "The results suggest that the huge amount of stress felt by pregnant mothers during these unprecedented times may have played a role."

The study did not measure maternal stress during pregnancy. Other possible factors including fewer play dates and altered interactions with stressed care givers, might also explain why babies born during the pandemic have weaker social and motor skills than babies born before the pandemic. The researchers will continue to follow the infants in longer term studies.

Research published last year as a preprint found that babies born during the pandemic scored lower on standard measures of verbal, motor, and overall cognitive ability. ${ }^{23}$ The longitudinal study of 672 children from Rhode Island that has run since 2011 found that babies born after the pandemic began showed a drop of 22 points on the Mullen scales of early learning.

Shuffrey LC, Firestein MR, Kyle MH, etal. Association of birth during the covid-19 pandemic with neurodevelopmental status at 8 months in infants with and without in utero exposure to maternal SARS-CoV-2 infection. JAMA Pediatr 2022;e215563.

doi: 10.1001/jamapediatrics.2021.5563. pmid: 34982107

2 Dyer 0. Covid-19: Children born during the pandemic score lower on cognitive tests, study finds. BMJ2021;374:n2031. doi: 10.1136/bmi.n2031. pmid: 34400436

3 Deoni SCL, Beauchemin J, Volpe A, etal. Impact of the covid-19 pandemic on early child cognitive development: initial findings in a longitudinal observational study of child health. Medrxiv 2021.08.10.21261846 [Preprint]. doi: 10.1101/2021.08.10.21261846

This article is made freely available for personal use in accordance with BMJ's website terms and conditions for the duration of the covid-19 pandemic or unti otherwise determined by BMJ. You may download and print the article for any lawful, non-commercial purpose (including text and data mining) provided that all copyright notices and trade marks are retained. 